\title{
Original Article \\ Development and Validation of a HPLC Method of Quantification of Caffeine and EGCG in Green Tea (Camellia sinensis L.) Extract
}

\author{
Tran Trong Bien ${ }^{1, *}$, Bui Thi Lan Phuong ${ }^{1,2}$ \\ ${ }^{1}$ Hanoi University of Pharmacy, 13-15 Le Thanh Tong, Hoan Kiem, Hanoi, Vietnam \\ ${ }^{2}$ National Institute of Pharmaceutical Technology, 13-15 Le Thanh Tong, Hoan Kiem, Hanoi, Vietnam
}

Received 23 February 2020

Revised 27 February 2020; Accepted 03 March 2020

\begin{abstract}
This study investigates a simple high performance liquid chromatography (HPLC) in an isocratic eluent manner for quantification of caffeine and EGCG in green tea extract. The study separation system contained a C18-RP column $(250 \times 4.6 \mathrm{~mm}, 5 \mu \mathrm{m})$, a mobile phase of methanol/phosphoric acid/water (20/0.1/79.9, v/v) and a DAD detector at $280 \mathrm{~nm}$. This system proves convenient for rapid routine analysis of caffeine and EGCG in green tea extract with good repeatability and accuracy.
\end{abstract}

Keywords: HPLC, caffeine, EGCG, green tea, extract.

\footnotetext{
${ }^{*}$ Corresponding author.

E-mail address: trantrongbien@gmail.com

https://doi.org/10.25073/2588-1132/vnumps.4212
} 


\title{
Xây dựng và thẩm định phương pháp HPLC định lượng cafein và EGCG trong cao lá Chè xanh (Camellia sinensis L.)
}

\author{
Trần Trọng Biên ${ }^{1, *}$, Bùi Thị Lan Phương ${ }^{1,2}$ \\ ${ }^{1}$ Truoòng Đại học Dược Hà Nội, 13-15 Lê Thánh Tông, Hoàn Kiếm, Hà Nội, Việt Nam \\ ${ }^{2}$ Viện Công nghệ Dược phẩm Quốc gia, 13-15 Lê Thánh Tông, Hoàn Kiếm, Hà Nội, Việt Nam \\ Nhận ngày 23 tháng 02 năm 2020 \\ Chỉnh sửa ngày27 tháng 02 năm 2020; Chấp nhận đăng ngày 02 tháng 03 năm 2020
}

\begin{abstract}
Tóm tắt: Một phương pháp HPLC với chế độ rửa giải đẳng dòng được nghiên cứu để định lượng cafein và EGCG trong cao lá Chè xanh. Điều kiện sắc ký gồm cột C18-RP $(250 \times 4,6 \mathrm{~mm}, 5 \mu \mathrm{m})$, pha động methanol/phosphoric acid/water (20/0,1/79,9, tt/tt) và detector DAD tại bước sóng 280 $\mathrm{nm}$. Phương pháp xây dựng thuận lợi để phân tích nhanh cafein và EGCG trong các mẫu cao lá Chè xanh với độ lặp lại và độ đúng tốt.
\end{abstract}

Tù khóa: HPLC, cafein, EGCG, Chè xanh.

\section{Mở đầu}

Chè (Camellia sinensis L.) là một trong những đồ uống phổ biến nhất ở Việt Nam và trên thế giới do hương vị đặc trưng và các tác dụng sinh học quan trọng của các hợp chất catechin (điển hình là epigallocatechin gallat - EGCG) trong lá như chống oxy hóa, chống viêm, kháng khuẩn, kháng virus, chống ung thư [1-3]. Ngoài ra, lá Chè xanh chứa 2-5\% cafein - một alcaloid khi sử dụng thường xuyên và quá mức sẽ gây kích ứng đường tiêu hóa; hồi hộp, mất ngủ; nhịp tim nhanh, tăng huyết áp; nguy cơ dị tật thai nhi, sẩy thai và thai chết lưu $[4,5]$. Do đó, hiện nay nhu cầu về các sản phẩm chứa hàm lượng cafein thấp từ cây Chè nói riêng và các loại đồ uống nói chung đang ngày càng tăng. Trong công nghiệp dược phẩm, cao chiết Chè xanh chuẩn hóa (Polyphenon ${ }^{\circledR} \mathrm{E}$, Theaphenon ${ }^{\circledR} \mathrm{E}$ ) đã được sản xuất đã và đang trải qua nhiều thử nghiệm lâm sàng quan trọng [2]. Một trong các thuốc đã được FDA chấp nhận trong điều trị mụn cóc sinh dục (Condyloma acuminata) từ năm 2006 dưới tên thương mại Veregen ${ }^{\circledR}$ (hoạt chất Sinecatechins) [6]. Cho đến nay, chưa có nghiên cứu nào trong nước đề cập đến việc loại cafein đồng thời làm giàu catechin trong điều chế cao lá Chè xanh loại cafein ứng dụng trong dược phẩm mặc dù Việt Nam là một trong những quốc gia sản xuất và tiêu thụ Chè lớn trên thế giới và Chè Việt Nam được đánh giá là có chất lượng ngang bằng với Chè Trung Quốc, Nhật Bản hay Australia [7]. Hiện tại, chúng tôi đang nghiên cứu điều chế các sản phẩm cao lá Chè loại cafein. Do đó, một phương pháp HPLC đơn giản đã được xây dựng và thẩm định nhằm định lượng đồng thời cafein và EGCG trong các mẫu cao phục vụ cho nghiên cứu.

\section{Nguyên vật liệu và phương pháp nghiên cứu}

\subsection{Nguyên vật liệu}

Mẫu nghiên cứu: Các mẫu cao nghiên cứu được chuẩn bị theo quy trình tham khảo [8], tóm tắt như sau:

\footnotetext{
"Tác giả liên hệ.

Địa chi email: trantrongbien@gmail.com

https://doi.org/10.25073/2588-1132/vnumps.4212
} 
Cao thô ethanol 50\%: lá Chè xanh khô thu hái tại Đại Từ, Thái Nguyên (kích thước 1-2 mm) được chiết xuất bằng phương pháp ngâm ở nhiệt độ phòng, chiết 3 lần $\times 12$ giờ với tỷ lệ dung môi gấp 10 lần nguyên liệu, gộp các dịch chiết và cô thu hồi dung môi dưới áp suất giảm (500 mbar, $70^{\circ} \mathrm{C}$ ) đến khi còn $1 / 3$ thể tích và phun sấy tạo cao khô với các điều kiện: nhiệt độ đầu vào $140^{\circ} \mathrm{C}$, nhiệt độ đầu ra $67-70^{\circ} \mathrm{C}$, tốc độ bơm 30 - 35\%, áp suất phun dịch $100 \%$, áp suất khí nóng 400 - 600 mbar, áp suất khí âm -40 mbar

Cao tinh chế loại cafein: dịch chiết lá Chè xanh với nồng độ cafein $0,5 \mathrm{mg} / \mathrm{mL}$ được điều chỉnh về $\mathrm{pH} 4$ bằng acid citric khan, thêm chất hấp phụ montmorillonit (tỷ lệ 3,5\% kl/tt), khuấy hỗn hợp trong 20 phút với tốc độ 150 vòng/phút ở $15-25^{\circ} \mathrm{C}$. Hỗn hợp sau hấp phụ được để lắng, gạn, lọc thu lấy dịch chiết đã loại cafein và đông khô (tiền đông $-70^{\circ} \mathrm{C}$ trong 24 giờ, thăng hoa 24 giờ ở $\left.-40^{\circ} \mathrm{C}, 0,1 \mathrm{mbar}\right)$.

Cao tinh chế giàu EGCG: dịch chiết lá Chè xanh sau loại cafein được pha loãng để được nồng độ EGCG là $0,5 \mathrm{mg} / \mathrm{mL}$ và hấp phụ qua cột nhựa macroporous HPD826. Rửa tạp chất bằng nước và giải hấp phụ bằng ethanol $30 \%$. Dịch giải hấp phụ được cô thu hồi ethanol dưới áp suất giảm $\left(500 \mathrm{mbar}, 70^{\circ} \mathrm{C}\right)$ và đông khô với điều kiện như trên.

Chất chuẩn: cafein chuẩn (hàm lượng 98,73\%, lô MUST-17060110) và EGCG chuẩn (hàm lượng 99,78\%, lô MUST-17060113) từ Chengdu Must Biological Technology Co., Ltd. (Trung Quốc).

Thiết bị: máy sắc kí lỏng hiệu năng cao Shimadzu (Nhật Bản) với các bộ phận chính: bơm cao áp LC-10ADVP, buồng cột CTO10AVP, bộ phận điều khiển SCL-10AVP, detector mảng diod SPD-M10AVP, bộ phận đuổi khí DGU-14A, phần mềm điều khiển Class vp 6.14.

\subsection{Phuơng pháp định luợng cafein và EGCG}

Tham khảo các tài liệu [3,9], các điều kiện HPLC được lựa chọn gồm: Cột C18 InertSustain ${ }^{\circledR}(250 \times 4,6 \mathrm{~mm}, 5 \mu \mathrm{m})$; pha động methanol - nước - acid phosphoric (20:79,9: $0,1, \mathrm{tt} / \mathrm{tt}$ ); tốc độ dòng: $0,8 \mathrm{~mL} /$ phút; thể tích tiêm mẫu: $20 \mu \mathrm{L}$; detector DAD tại $280 \mathrm{~nm}$.
Mẫu chuẩn: dung dịch chuẩn hỗn hợp hoặc chuẩn đơn trong nước cất có nồng độ nằm trong khoảng từ 8 đến $200 \mu \mathrm{g} / \mathrm{mL}$ đối với cafein và từ 12 đến $300 \mu \mathrm{g} / \mathrm{mL}$ đối với EGCG.

Mẫu thử: Cân chính xác khoảng $10 \mathrm{mg}$ cao khô vào bình định mức $100 \mathrm{~mL}$, hòa tan và bổ sung nước cất đến vạch, pha loãng đến nồng độ thích hợp và lọc qua màng cellulose acetat 0,45 $\mu \mathrm{m}$. Hàm lượng cafein (hoặc EGCG) trong mẫu thử được tính theo công thức:

$$
\text { Hàm lượng }(\%)=\frac{\left(S_{t}-b\right) \times k \times 10000}{a \times 1000 \times m_{t} \times(100-B)}
$$

Trong đó, $\mathrm{S}_{\mathrm{t}}$ là diện tích píc sắc ký của cafein (hoặc EGCG) trong mẫu thử, a và b là các hệ số của đường chuẩn $(\mathrm{y}=\mathrm{ax}+\mathrm{b})$ của cafein (hoặc EGCG), $\mathrm{k}$ là hệ số pha loãng của mẫu thử, $\mathrm{m}_{\mathrm{t}}$ là khối lượng mẫu thử $(\mathrm{g}), \mathrm{B}$ là hàm ẩm của mẫu thử $(\%)$.

\section{Thực nghiệm và kết quả}

\subsection{Thẩm định phương pháp định luợng}

Độ đặc hiệu: tiến hành sắc ký các mẫu sau: mẫu trắng (nước cất), chuẩn đơn cafein, chuẩn đơn EGCG, chuẩn hốn hợp và mẫu thử thu được các sắc ký đồ như Hình 1 .

Cafein có thời gian lưu khoảng 18 phút, EGCG có thời gian lưu khoảng 21 phút. Trên sắc ký đồ mẫu trắng không xuất hiện tín hiệu píc tại các thời gian lưu này và trên sắc ký đồ mẫu chuẩn hỗn hợp và mẫu thử có tín hiệu píc của 2 hoạt chất tại các thời gian lưu tương ứng. Như vậy, phương pháp HPLC có tính đặc hiệu phù hợp theo yêu cầu. Ngoài ra, độ phân giải giữa 2 píc cafein và EGCG trên sắc ký đồ mẫu chuẩn hỗn hợp và mẫu thử là 4,834 và 3,662 tương ứng (đều lớn hơn 1,5) chứng tỏ 2 píc tách nhau hoàn toàn và chương trình sắc ký đã chọn có khả năng tách và định lượng 2 hoạt chất.

Độ thích hợp hệ thống: tiêm lặp lại 6 lần một mẫu chuẩn hỗn hợp có nồng độ cafein và EGCG tương ứng là 40 và $60 \mu \mathrm{g} / \mathrm{mL}$. Độ chênh lệch của diện tích píc và thời gian lưu của cafein và EGCG đều có RSD $<2 \%$, cho thấy các điều kiện sắc ký đã lựa chọn và hệ thống HPLC là phù hợp (Bảng 1). 

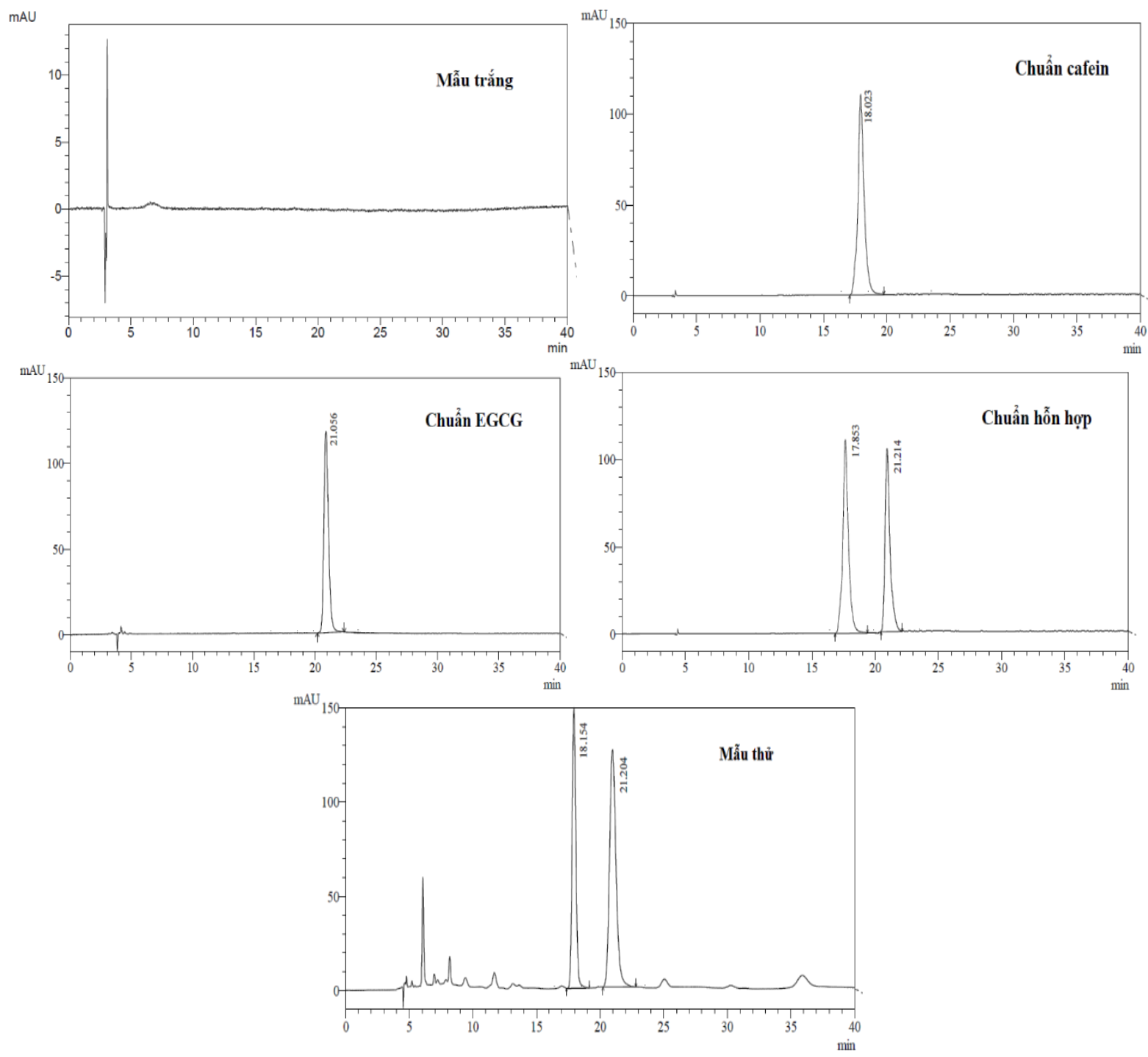

Hình 1. Sắc ký đồ HPLC thẩm định độ đặc hiệu.

Bảng 1. Kết quả thời gian lưu và diện tích píc của dung dịch chuẩn hỗn hợp

\begin{tabular}{|l|l|l|l|l|}
\hline \multirow{2}{*}{ Số thứ tự } & Cafein & EGCG & \multicolumn{2}{|l|}{} \\
\cline { 2 - 5 } & $\begin{array}{l}\text { Thời gian lưu } \\
\text { (phút) }\end{array}$ & $\begin{array}{l}\text { Diện tích píc } \\
\text { (mAU.s) }\end{array}$ & $\begin{array}{l}\text { Thời gian lưu } \\
\text { (phút) }\end{array}$ & $\begin{array}{l}\text { Diện tích píc } \\
\text { (mAU.s) }\end{array}$ \\
\hline 1 & 18,509 & 5070086 & 20,370 & 2618581 \\
\hline 2 & 18,619 & 4837789 & 20,856 & 2741833 \\
\hline 3 & 18,311 & 5111284 & 20,789 & 2694934 \\
\hline 4 & 18,541 & 5035115 & 20,548 & 2730358 \\
\hline 5 & 18,403 & 5099846 & 20,978 & 2689647 \\
\hline 6 & 17,988 & 5016688 & 21,001 & 2631101 \\
\hline Trung bình & 18,395 & 5028468 & 20,757 & 2684409 \\
\hline RSD $(\%)$ & 1,23 & 1,99 & 1,20 & 1,88 \\
\hline
\end{tabular}


Bảng 2. Mối tương quan giữa diện tích píc và nồng độ cafein và EGCG

\begin{tabular}{|l|l|l|l|l|}
\hline \multirow{2}{*}{ Số thứ tự } & \multicolumn{2}{|l|}{ Cafein } & EGCG & Niện tích píc \\
\cline { 2 - 5 } & Nồng độ $(\mu \mathrm{g} / \mathrm{mL})$ & $\begin{array}{l}\text { Diện tích píc } \\
\left(\mathrm{mAU}^{*} \mathrm{~s}\right)\end{array}$ & $\left.96 U^{*} \mathrm{~s}\right)$ \\
\hline 1 & 8,08 & 967556 & 12,16 & 696180 \\
\hline 2 & 40,40 & 4837789 & 60,80 & 2741833 \\
\hline 3 & 80,80 & 9874559 & 121,60 & 5744600 \\
\hline 4 & 121,20 & 13812256 & 182,40 & 8170966 \\
\hline 5 & 161,60 & 18751344 & 243,20 & 10645533 \\
\hline 6 & 202,00 & 23699875 & 304,00 & 13480099 \\
\hline $\begin{array}{l}\text { Phương trình } \\
\text { hồi quy }\end{array}$ & $\mathrm{y}=115975 \mathrm{x}+120868$ & $\mathrm{y}=43557 \mathrm{x}+204191$ \\
\hline $\mathrm{R}^{2}$ & 0,9991 & 0,9992 & \\
\hline
\end{tabular}
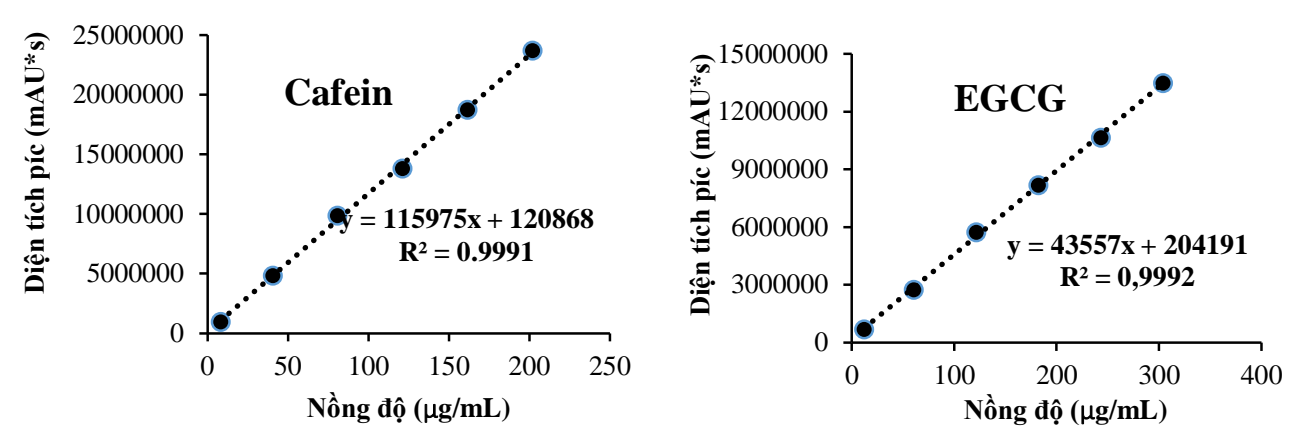

Hình 2. Đường chuẩn mối tương quan giữa diện tích píc và nồng độ.

Khoảng tuyến tính: kết quả khảo sát sự tương quan giữa diện tích píc và nồng độ cafein và EGCG được thể hiện trong Bảng 2 và Hình 2. Đường chuẩn của cafein và EGCG đều cho giá trị $\mathrm{R}^{2}>0,99$ thể hiện độ tuyến tính cao giữa diện tích và nồng độ chất phân tích.
Độ lặp lại: tiêm lặp lại 6 lần một mẫu thử cao lá Chè, kết quả đánh giá độ lặp lại của phương pháp được thể hiện ở Bảng 3. Trị số RSD của thời gian lưu và diện tích pic của cafein và EGCG đều nhỏ hơn $2 \%$ cho thấy phương pháp có độ lặp lại tốt.

Bảng 3. Kết quả khảo sát độ lặp lại của phương pháp định lượng

\begin{tabular}{|l|l|l|l|l|}
\hline \multirow{2}{*}{ Số thứ tự } & Cafein & EGCG & \multicolumn{2}{|l|}{} \\
\cline { 2 - 5 } & $\begin{array}{l}\text { Thời gian lưu } \\
\text { (phút) }\end{array}$ & $\begin{array}{l}\text { Diện tích píc } \\
\text { (mAU.s) }\end{array}$ & $\begin{array}{l}\text { Thời gian lưu } \\
\text { (phút) }\end{array}$ & $\begin{array}{l}\text { Diện tích píc } \\
\text { (mAU.s) }\end{array}$ \\
\hline 1 & 17,809 & 1073065 & 21,542 & 1964324 \\
\hline 2 & 18,241 & 1087642 & 21,234 & 1977534 \\
\hline 3 & 18,442 & 1056234 & 20,682 & 1923276 \\
\hline 4 & 18,354 & 1103894 & 20,487 & 1945273 \\
\hline 5 & 17,706 & 1063421 & 20,872 & 1913028 \\
\hline 6 & 18,202 & 1085429 & 21,123 & 1951203 \\
\hline Trung bình & 18,126 & 1078281 & 20,990 & 1945773 \\
\hline RSD (\%) & 1,65 & 1,62 & 1,84 & 1,25 \\
\hline
\end{tabular}


Độ đúng: trong các bình định mức 100 mL, chuẩn bị các dung dịch chuẩn như sau:

+ Chuẩn cafein: $0,0103 \mathrm{~g} \times 98,73 \% \times$ $1000000 \mu \mathrm{g} / \mathrm{g} / 100 \mathrm{~mL}=101,69 \mu \mathrm{g} / \mathrm{mL}$

+ Chuẩn EGCG: 0,0192 $\mathrm{g} \times 99,78 \% \times$ $1000000 \mu \mathrm{g} / \mathrm{g} / 100 \mathrm{~mL}=191,58 \mu \mathrm{g} / \mathrm{mL}$

Trong bình định mức $100 \mathrm{~mL}$, cân chính xác khoảng $10 \mathrm{mg}$ cao thô (đã biết hàm lượng cafein và $\mathrm{EGCG}$ tương ứng là 5,0 và $19,0 \%$ ). Dùng pipet chính xác thêm vào bình định mức các lượng chuẩn cafein và EGCG tương ứng với các mức 50,100 và $150 \%$ so với lượng chất phân tích đã có trong mẫu thử, hòa tan và pha loãng đến vạch bằng nước cất, lọc qua màng $0,45 \mu \mathrm{m}$. Kết quả khảo sát độ đúng được thể hiện ở Bảng 4 và Bảng 5.

Ở 3 mức thêm chuẩn, \% tìm lại trung bình của cafein đều nằm trong khoảng $97-103 \%$ và EGCG đều nằm trong khoảng $98-102 \%$ chứng tỏ phương pháp định lượng đáp ứng yêu cầu về độ đúng.

Bảng 4. Kết quả khảo sát độ đúng của cafein

\begin{tabular}{|c|c|c|c|c|c|c|c|}
\hline $\begin{array}{l}\% \text { chuẩn } \\
\text { thêm vào }\end{array}$ & $\begin{array}{l}\text { Khối } \\
\text { lượng cân } \\
\text { (g) }\end{array}$ & $\begin{array}{l}\text { Lượng có } \\
\text { sẵn }(\mu \mathrm{g})\end{array}$ & $\begin{array}{l}\text { Lượng } \\
\text { thêm vào } \\
(\mu \mathrm{g})\end{array}$ & $\begin{array}{l}\text { Diện tích píc } \\
\text { (mAu.s) }\end{array}$ & $\begin{array}{l}\text { Lượng } \\
\text { tìm thấy } \\
(\mu \mathrm{g})\end{array}$ & $\begin{array}{l}\% \text { thu } \\
\text { hồi }\end{array}$ & $\begin{array}{l}\text { \% tìm lại } \\
\text { trung bình }\end{array}$ \\
\hline \multirow{3}{*}{$50 \%$} & 0,0110 & 550 & 254,23 & 505229 & 797,67 & 97,42 & \multirow{3}{*}{98,20} \\
\hline & 0,0104 & 520 & 254,23 & 488302 & 770,77 & 98,64 & \\
\hline & 0,0107 & 535 & 254,23 & 497582 & 785,52 & 98,54 & \\
\hline \multirow{3}{*}{$100 \%$} & 0,0105 & 525 & 508,46 & 652564 & 1031,80 & 99,67 & \multirow{3}{*}{100,11} \\
\hline & 0,0104 & 520 & 508,46 & 643245 & 1016,99 & 97,74 & \\
\hline & 0,0100 & 500 & 508,46 & 647190 & 1023,26 & 102,91 & \\
\hline \multirow{3}{*}{$150 \%$} & 0,0103 & 515 & 762,69 & 799874 & 1265,88 & 98,45 & \multirow{3}{*}{98,58} \\
\hline & 0,0106 & 530 & 762,69 & 812145 & 1285,38 & 99,04 & \\
\hline & 0,0104 & 520 & 762,69 & 802084 & 1269,39 & 98,26 & \\
\hline
\end{tabular}

Bảng 5. Kết quả khảo sát độ đúng của EGCG

\begin{tabular}{|c|c|c|c|c|c|c|c|}
\hline $\begin{array}{l}\text { \% chuẩn } \\
\text { thêm vào }\end{array}$ & $\begin{array}{l}\text { Khối } \\
\text { lượng cân } \\
\text { (g) }\end{array}$ & $\begin{array}{l}\text { Lượng có } \\
\text { sằn }(\mu \mathrm{g})\end{array}$ & $\begin{array}{l}\text { Lượng } \\
\text { thêm vào } \\
(\mu \mathrm{g})\end{array}$ & $\begin{array}{l}\text { Diện tích píc } \\
\text { (mAu.s) }\end{array}$ & $\begin{array}{l}\text { Lượng } \\
\text { tìm thấy } \\
(\mu g)\end{array}$ & $\begin{array}{l}\% \text { thu } \\
\text { hồi }\end{array}$ & $\begin{array}{l}\text { \% tìm lại } \\
\text { trung bình }\end{array}$ \\
\hline \multirow{3}{*}{$50 \%$} & 0,0110 & 2090 & 957,89 & 1499783 & 3029,46 & 98,08 & \multirow{3}{*}{100,22} \\
\hline & 0,0104 & 1976 & 957,89 & 1463013 & 2945,45 & 101,21 & \\
\hline & 0,0107 & 2033 & 957,89 & 1488723 & 3004,19 & 101,39 & \\
\hline \multirow{3}{*}{$100 \%$} & 0,0105 & 1995 & 1915,78 & 1874786 & 3886,32 & 98,72 & \multirow{3}{*}{99,87} \\
\hline & 0,0104 & 1976 & 1915,78 & 1888279 & 3917,15 & 101,32 & \\
\hline & 0,0100 & 1900 & 1915,78 & 1840284 & 3807,49 & 99,57 & \\
\hline \multirow{3}{*}{$150 \%$} & 0,0103 & 1957 & 2873,66 & 2298364 & 4854,17 & 100,82 & \multirow{3}{*}{99,39} \\
\hline & 0,0106 & 2014 & 2873,66 & 2296098 & 4848,99 & 98,65 & \\
\hline & 0,0104 & 1976 & 2873,66 & 2280123 & 4812,49 & 98,71 & \\
\hline
\end{tabular}

Giới hạn phát hiện và giới hạn định lượng: Giới hạn phát hiện (LOD) và giới hạn định lượng (LOQ) được xác định bằng cách pha loãng dần một dung dịch chuẩn, ghi lại sắc ký đồ và xác định tỷ lệ tín hiệu píc/nhiễu đường nền $(\mathrm{S} / \mathrm{N})$, LOD được xác định tại nồng độ có $\mathrm{S} / \mathrm{N} \sim 3$ và LOQ được xác định tại nồng độ có $\mathrm{S} / \mathrm{N} \sim 10$. Kết quả cho thấy, cafein có $\mathrm{LOD}=0,05 \mu \mathrm{g} / \mathrm{mL}$,
$\mathrm{LOQ}=0,2 \mu \mathrm{g} / \mathrm{mL}$. EGCG có $\mathrm{LOD}=0,2 \mu \mathrm{g} / \mathrm{mL}$, $\mathrm{LOQ}=0,5 \mu \mathrm{g} / \mathrm{mL}$.

\section{2. Úng dụng phương pháp HPLC dịnh lương môt số mẫu cao}

Phương pháp HPLC xây dựng và thẩm định được ứng dụng để định lượng hàm lượng EGCG 
và cafein trong một số mẫu lá cao, kết quả được trình bày ở Bảng 6 và Hình 3. Có thể thấy, phương pháp HPLC cho kết quả có độ lặp lại tốt. Phương pháp loại cafein và làm giàu EGCG đã cho thấy được mức độ hiệu quả, khi so sánh hàm lượng cafein và EGCG trong các mẫu cao thô và các mẫu cao tinh chế.

Bảng 6. Kết quả định lượng một số mẫu cao Chè (n=3)

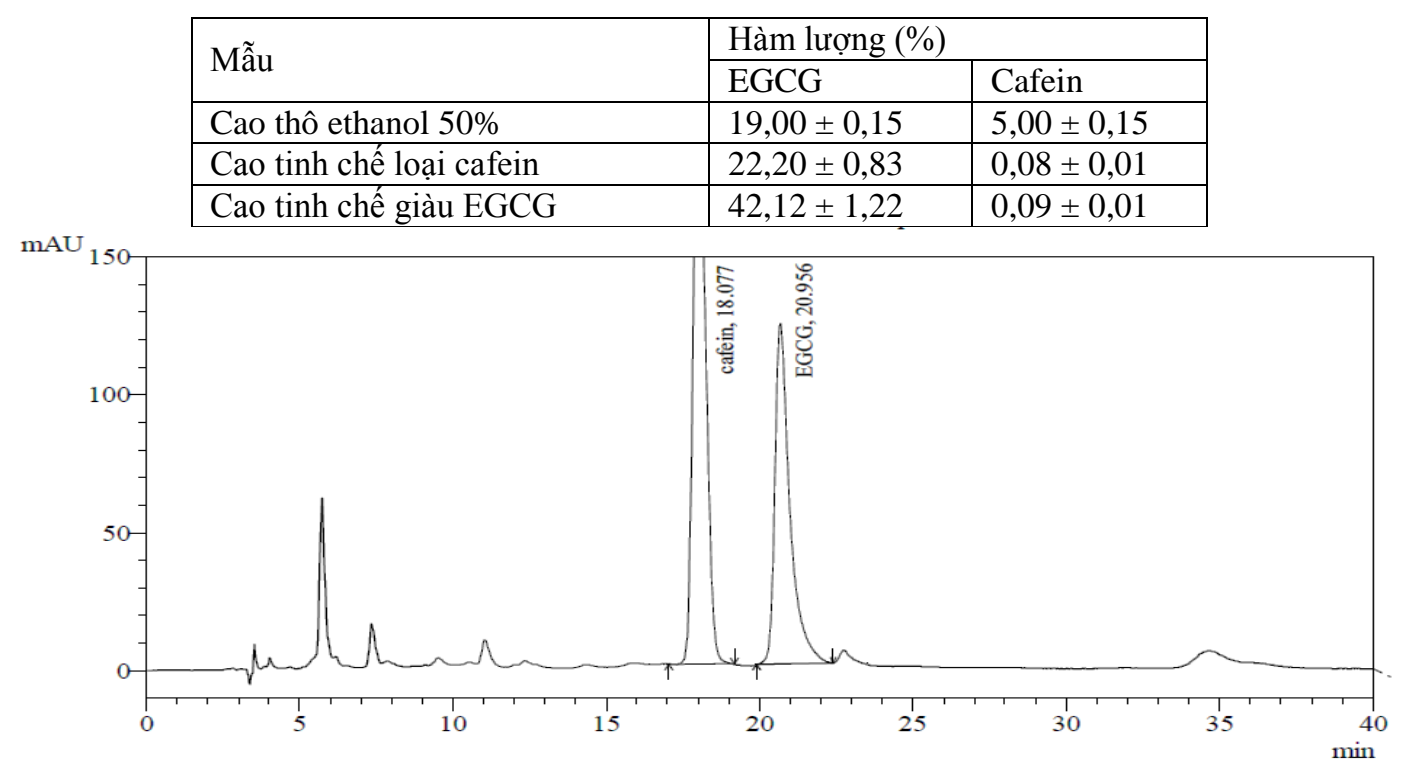

Mẫu cao thô ethanol 50\%

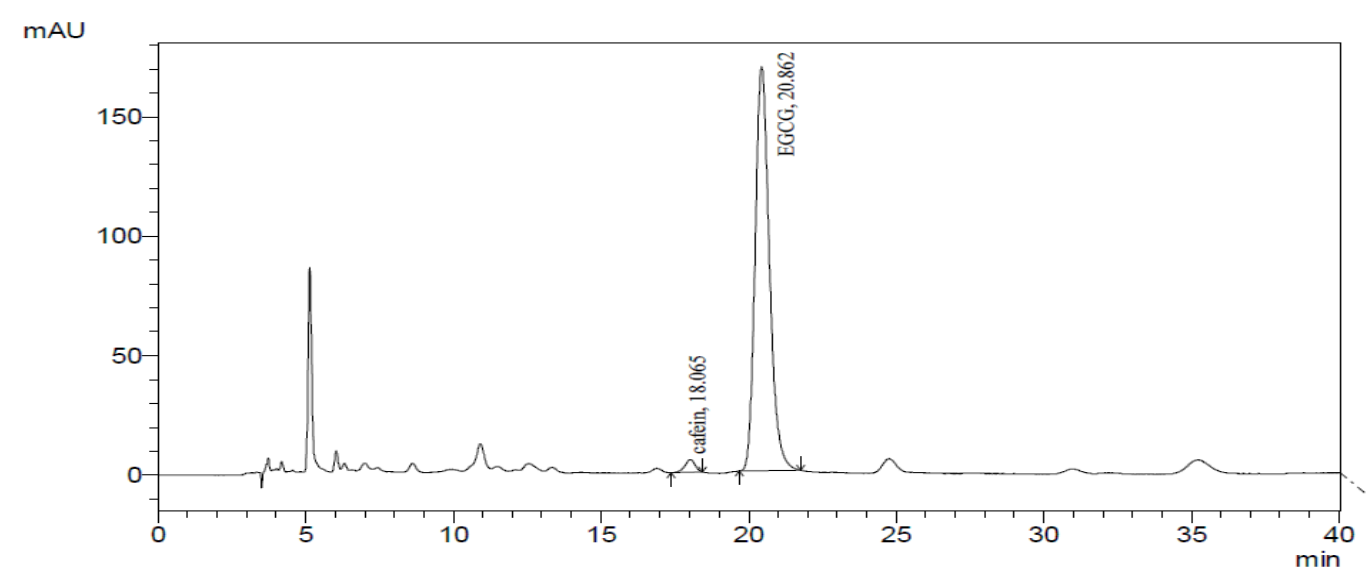

Mẫu cao sau loại cafein 


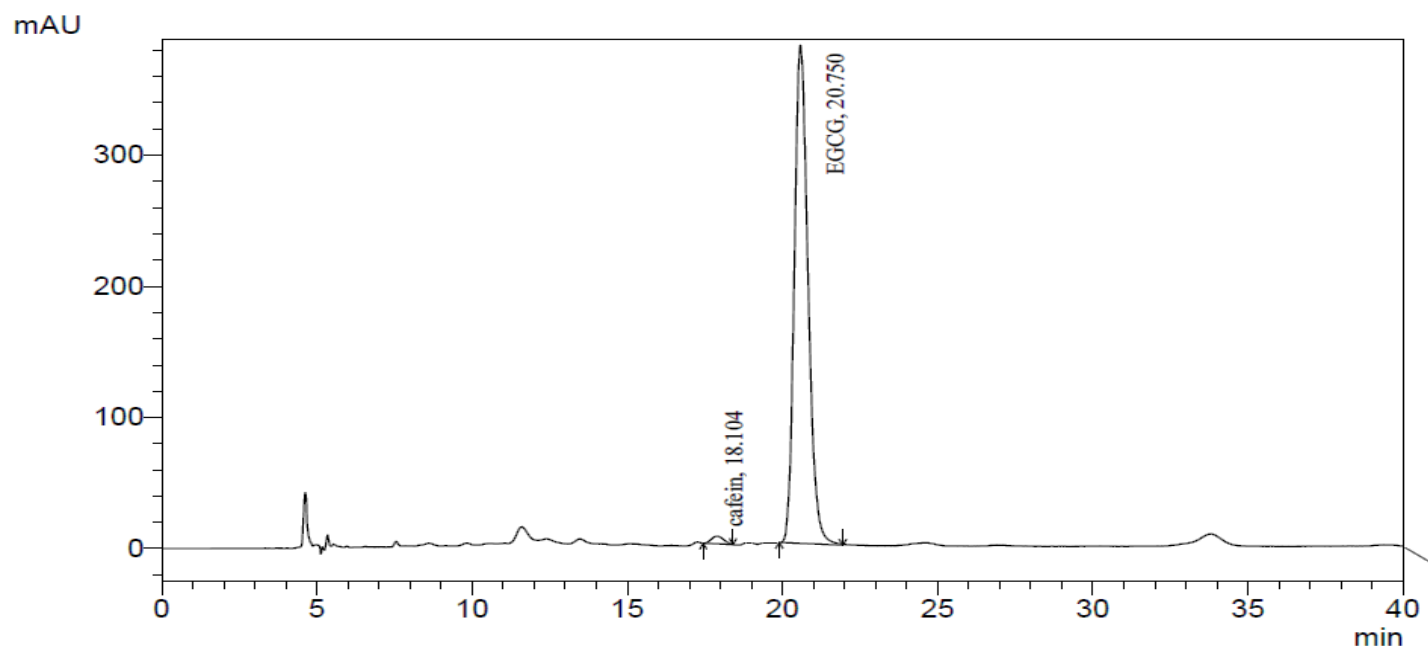

Mẫu cao sau loại cafein và làm giàu EGCG

Hình 3. Sắc ký đồ HPLC một số mẫu thử.

\section{Bàn luận}

Để kiểm nghiệm các thành phần trong cao lá Chè xanh, một số phương pháp đã được nghiên cứu và áp dụng. Trong đó, phương pháp sắc ký lỏng hiệu năng cao (HPLC) và điện di mao quản (CE) là 2 phương pháp được nghiên cứu nhiều nhất. Phương pháp HPLC với detector UV tỏ ra thông dụng và phổ biến, ngoài ra các detector khác như khối phổ, điện hóa, huỳnh quang cũng được sử dụng trong những trường hợp cần thiết. Một số phương pháp khác như sắc ký khí, sắc ký lớp mỏng, sắc ký giấy, quang phổ, phổ cộng hưởng tử hạt nhân cũng được sử dụng để phân tích định tính các thành phần trong Chè xanh [9]. Với phương pháp HPLC, đa phần các nghiên cứu xây dựng chương trình rửa giải gradient nồng độ dung môi khá phức tạp. Jun X. et al. sử dụng hệ pha động $\mathrm{A}(0,05 \%$ acid phosphoric $0,05 \%)$ và $\mathrm{B}$ (acetonitril) với chương trình thay đổi từ $90: 10$ $(\mathrm{A}: \mathrm{B}, \%)$ đến 70:30 (A:B，\%) theo chế độ gradient trong 30 phút [3]. Shiono $\mathrm{T}$. et al. sử dụng cột $\mathrm{C}_{18}(4,6 \mathrm{~mm} \times 150 \mathrm{~mm}, 3 \mathrm{~mm})$, hệ pha động gồm $\mathrm{A}=$ nước/acetonitril/acid phosphoric $(1000 / 25 / 1,0, \mathrm{tt} / \mathrm{tt}), \mathrm{B}=$ nước/methanol/acetonitril /acidphosphoric $\quad(600 / 300 / 15 / 0,6, t \mathrm{tt} / \mathrm{tt}) \quad$ và $\mathrm{C}=$ methanol/acetonitril/acidphosphoric $(800 / 200$ $/ 1,0, \mathrm{tt} / \mathrm{tt})$, rửa giải gradient trong 24 phút [10]. Có thể thấy, tùy theo mục đích của nghiên cứu và các điều kiện kỹ thuật sẵn có, các điều kiện HPLC được các tác giả sử dụng khác nhau. Trên cơ sở tham khảo các tài liệu, phương pháp HPLC rửa giải theo chế độ đẳng dòng đã được xây dựng phù hợp với điều kiện phòng thí nghiệm và được thẩm định các chỉ tiêu cơ bản như độ đặc hiệu, độ thích hợp hệ thống, khoảng tuyến tính, độ lặp lại, độ đúng, giới hạn phát hiện và giới hạn định lượng. Kết quả thẩm định đáp ứng các yêu cầu cơ bản của phép định lượng, cho phép xác định chính xác hàm lượng cafein và $\mathrm{EGCG}$ trong các mẫu thử trong thời gian tương đối ngắn với các điều kiện sắc ký đơn giản.

\section{Kết luận}

Phương pháp HPLC với chế độ rửa giải đẳng dòng đã được nghiên cứu để định lượng cafein và EGCG trong cao lá Chè xanh. Điều kiện sắc ký gồm cột C18-RP $(250 \times 4,6$ mm, $5 \mu \mathrm{m})$, pha động methanol/phosphoric acid/water $(20 / 0,1 / 79,9, \mathrm{tt} / \mathrm{tt})$ và detector $\mathrm{DAD}$ tại bước sóng $280 \mathrm{~nm}$. Các chỉ tiêu thâm định phương pháp phân tích như độ đặc hiệu, độ thích hợp hệ thống, khoảng tuyến tính, độ lặp lại, độ đúng, giới hạn phát hiện và giới hạn định lượng đều đạt yêu cầu. Phương pháp xây dựng thuận lợi để phân tích nhanh cafein và EGCG trong cao lá Chè xanh. 


\section{Tài liệu tham khảo}

[1] A. Chowdhury, J. Sarkar, T. Chakraborti, P.K. Pramanik, S. Chakraborti, Protective role of epigallocatechin-3-gallate in health and disease: A perspective, Biomedicine \& Pharmacotherapy 78 (2016) 50-59. https://doi.org/10.1016/j.biopha.2015.12.013.

[2] Y. Hara, Tea catechins and their applications as supplements and pharmaceutics, Pharmacological Research 64(2) (2011) 100-104. https://doi.org/10.1016/j.phrs.2011.03.018.

[3] X. Jun, S. Zhao, B. Lu, R. Zhang, Y. Li, D. Shen, G. Zhou, Separation of major catechins from green tea by ultrahigh pressure extraction, International Journal of Pharmaceutics 386(1-2) (2010) 229-231. https://doi.org/10.1016/j.ijpharm.2009.10.035.

[4] Z. Bedrood, M. Rameshrad, H. Hosseinzadeh, Toxicological effects of Camellia sinensis (green tea): A review, Phytotherapy Research 32(7) (2018) 1163-1180.

https://doi.org/10.1002/ptr.6063.
[5] J.M. Glade, Caffeine-Not just a stimulant, Nutrition 26(10) (2010) 932-938. https://doi.org/10.1016/j.nut.2010.08.004.

[6] MediGene AG. Press Release., MediGene AG Obtains Approval of Polyphenon ${ }^{\circledR} \mathrm{E}$ Ointment in the USA, 2006.

[7] Q.V. Vuong, V. Nguyen, J.B. Golding, P.D. Roach, The content of bioactive constituents as a quality index for Vietnamese teas, International Food Research Journal 18(1) (2011) 329-336.

[8] Tran Trong Bien, Method for caffeine removal and catechins enrichment from green tea leaf, Master thesis, Hanoi University of Pharmacy, 2019 (In Vietnamese).

[9] J.J. Dalluge, C.B. Nelson, Determination of tea catechins, Journal of Chromatography A 881 (2000) 411-424. https://doi.org/10.1016/S0021-9673(00)00062-5.

[10] T. Shiono, et al., Selective decaffeination of tea extracts by montmorillonite, Journal of Food Engineering 200 (2017) 13-21.

https://doi.org/10.1016/j.jfoodeng.2016.12.015. 